\title{
A Systematic Review on The Definition of Children's Number Sense in the Primary School Years
}

\author{
Munirah Ghazali ${ }^{1,2^{\star}}$, Rosmawati Mohamed ${ }^{1}$, Zainun Mustafa ${ }^{2}$ \\ ${ }^{1}$ School of Educational Studies, Universiti Sains Malaysia, MALAYSIA \\ ${ }^{2}$ Regional Centre of Expertise for ESD, RCE Penang, Universiti Sains Malaysia, MALAYSIA
}

Received 17 September 2020 - Accepted 22 December 2020

\begin{abstract}
The definitions serve the purpose of communication and preservation of knowledge in scientific inquiry. However, it is quite often to perceive number sense concept without well-accepted definitions in the field of mathematics education research. Despite the mentioned issue, the current literature on children's number sense provide a glean for introducing, implementing, and even measuring the number sense using the specific and contextualized indicators in early mathematics. Consequently, this phenomenon offers to bridge a gap in the literature concerning definitions of number sense and its indicators. This article systematically reviews on the indicators in measuring children's number sense based on the past research guided by the PRISMA statements. The metadata were analysed using open-coding and were further re-coded through axial coding and selective coding to form a definition of number sense. This article discusses on limitations, implications, and the future research directions for studying children's number sense in the primary schools' mathematics.
\end{abstract}

Keywords: systematic review, number sense; numeracy; definition; mathematics education

\section{INTRODUCTION}

The term "number sense" is widely used in recent years' curricula reforms, as reported in the Encyclopedia of Mathematics Education (Pitta-Pantazi, 2014). The significance of number sense in mathematics curricula is well recognized; however, its description and definition are somewhat elusive. For instance, the National Council of Teachers of Mathematics (NCTM) refers the "students with number sense naturally decompose numbers, use particular numbers as referents, solve problems using the relationships among operations and knowledge about the baseten system, estimate a reasonable result for a problem, and have a disposition to make sense of numbers, problems, and results" (NCTM, 2000). As compared to the broad aspect that the number sense is in the mentioned definition, the number sense also referred to a very confined terms. To illustrate, Reynvoet, Smets, and Sasanguie (2016) suggests that the "number sense is the ability to represent the number of both non-symbolic and symbolic stimuli" innately. However, the argument stated by Reynvoet et al. (2016) was contradicted with the study by Leibovich, Katzin, Harel, and Henik (2017) who claimed that number sense is not innate and automatic as previously thought. The challenges in defining number sense also highlighted by other researcher (Ghazali, 2004; Lee \& Lembke, 2016; Yang, Li, \& Lin, 2008).

The lack of consistent definitions does not only weaken the significance of research findings, but this also contributes to obstacles in academic communication and consequently produces the misunderstanding of what number sense is. The concept of number sense studied in animal and infant, cognitive psychologist, neurologist, and mathematical educationalist were differently conceptualized (Dehaene, 2011). In regard of mathematics education, the complexities and variation of how number sense is acquired were also rooted in student's development of cognitive abilities (Y1lmaz, 2017). It means that the current literature agreed that the misunderstanding of what number sense is derived from the field the number sense is notably studied in mathematics education - is the age of the students.

Even though the definition of number sense is ambivalent, the importance of number sense is prevailed (Kuldas, Sinnakaudan, Hashim, \& Ghazali, 2017).

(c) 2021 by the authors; licensee Modestum. This article is an open access article distributed under the terms and conditions of the Creative Commons Attribution License (http://creativecommons.org/licenses/by/4.0/).

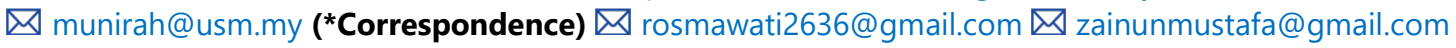




\section{Contribution to the literature}

- This paper systematically reviewed the concept of number sense in the primary years' mathematics education.

- From the reviews, this article carefully proposed the operational definition, imposed definition, inductive definition and verbal definition of number sense by synthesizing the possible indicators of number sense in the past studies.

- This study also developed a flowchart for definition formulation using SLR+PRISMA through three coding stages.

Hence, the research on children's number sense ability in primary school years are well documented. The past studies have applied different indicators to conceptualize the number sense in primary mathematics education. This article seeks to formulate a definition of number sense inductively from the indicators (i.e., construct, criteria, attribute, and isolates) which were used to measure the number sense in primary school students. Therefore, this study aims to formulate a definition of number sense based on indicators documented in previous studies in the perspectives of primary year's mathematics education. As compared to the common practice of formulating definition from theoretical or literal interpretation, the formulation of definitions of number sense in this article is by synthesizing the possible indicators of number sense in the past studies.

The grasp in the definition of number sense specifically in primary year's mathematics education is crucial to make possible verification and reproduction of the observations by others and checking the findings. The insight of the number sense definition and its indicators serve as a general guideline for researchers and teacher alike. The intensive analysis of indicators of number sense has directed to an informed decision and evidence-based sound plan to create and inform the current practice, center upon primary mathematics education.

\section{LITERATURE REVIEW}

Number sense is a critical part of mathematics instruction and curricular globally. The existing evidence discussed that number sense forms an essential foundation for understanding mathematical concepts that will be needed in later life (Voronin, Ovcharova, Bezrukova, \& Kovas, 2018). Despite the large volume of the published documents concerning number sense, to date, a much objective definition is still not formulated in the perspectives of primary school mathematics education. For instance, the existing research views different representations of numbers as a number sense strategy (Carroll, Fuson, \& Diamond, 2000). Furthermore, another study investigated by Kerschen, Cooper, Shelton, \& Scott, 2018) lamented that the number sense partly identifies relative and absolute magnitudes of numbers. Whereas, some researchers tend to imply number sense as the composition and decomposition of numbers (Howell \& Kemp, 2010). At much consecutive extend, some research denote the conceptual understanding of operations (Yang et al., 2008) or even estimation as the conceptual definition number sense (Kim, Shin, \& Lee, 2013). Number sense also refers to mental computations (Lee \& Lembke, 2016) or the ability to make a judgment about the reasonableness of a calculation (Yang \& Hsu, 2009).

The genesis of the term 'number sense' traced from historical perspectives indicated that indexed literature before 1800 about number sense "does not make any sense" as it was related to sociology, art, theology, and even politics. From the N-Gram viewer provided by Google, the linguistic link of number sense has been put upfront in the literature for more than 200 years since the 1890s. Several earliest works conducted by Crawley (1897), and Conant (1893) yielded the discussions regarding the origin of the numbering system and philosophical underpinning of number sense. Despite early notes in published works, this term first appeared in the Scopus database was a review paper written by Riess (1943). She compared several previous experiments and attempted to propose an early theoretical underpinning regarding the numerical quantification and number sense from behavioural perspectives. This classic article revealed that systematic research concerning numeric sense-making research interest during that time was to understand human abilities and capabilities as compared to animals. To date, the research in number sense has been revolutionized and embarked to uncover in different area of studies. The collective research approach across the historical timeline until present has revealed the multitude of research approaches and could be a remark of more scientific revenues in the future.

What is the definition of number sense? As discussed earlier, the cognitive scientist might already arrive to a much converged definition (Reynvoet et al., 2016), but the mathematics educationalists were quite diverged (NCTM, 2000). From the classical perspective of social sciences, 'definition' consists of 'words, and words are symbols representing ideas or facts, that is, singled-out states of knowable reality' (Timasheff, 1947). He further explained that the definition which covers scientifically relevant conjunction of attributes or a suitable isolate 
considered must scientifically adequate. To illustrate, the typology of definition provides distinction of definition criteria, namely verbal, inductive, imposed, and operational.

The verbal definition refers to the meaning of the terms designated in speech or the word's etymology. Gupta (2019) referred to the verbal definition as a nominal definition. 'Number sense' is expressed as a single concept in literature; the terms are absent in the dictionary (i.e., Merriam-Webster, Cambridge, and Oxford). Meanwhile, the inductive definition associates with the formulation of definitions by forming logical implications from inferences. Other researchers mention the inductive definition as inductive conceptualization (see, e.g., São José et al., 2019). Amongst all of the four types of definition, the number sense referred in literature is mostly either imposed or operational. The imposed definition refers to deductive reasoning accompanied by additional examples (see, e.g., Xinkui, 2019). The operational definition relates to observable operations, measured variables, and underlying prior assumptions (Shoemaker, Tankard Jr, \& Lasorsa, 2003).

The past research embarked on the qualitative paradigm, frequently utilizing the imposed definition as compared to the quantitative research incline towards an operationalized definition. These differences may derive from the nature and limitation of the different research paradigms. The in-depth research from qualitative realms apt to deduce the concept of number sense. Therefore, rather than a comprehensive one-fits-for-all definition, number sense is segmented according to a particular topic. For example, number sense concept was narrowed spatially and temporally (Cheek, 2013), arithmetic (Alsawaie 2012), and fraction (Rendell, 2008). On the other side, the operational definition fits well with the usage of the construct, or principles, scale which contributed mainly by the norm-referred instrumentation such as TEMA in Clarke et al. (2018), CBM-IPAM in de León et al. (2020) or contextuallyadapted-framework to assess school children's number sense asses (Zanzali \& Ghazali, 1999). The findings from advanced statistical analysis of the norm-referred quantitative data mostly applied to a broader context. Therefore, the selection of definitions and tailored research agenda are referred to the criterion of certain indicator to measure the abstract concept of number sense.

In this article, number sense indicators refer to the collective observable outcome from the number sense concept implemented in the research as cases, attributes, statements, variables, and embodied ideas of number sense regardless of the research paradigm. It means that the indicators of number sense portrayed as observable features or measurable facets used in previous study to learn the concept number sense in primary mathematics education. In the formulation of the definition of number sense, the procedure consists of suggesting a definition by referring to some common and essential attributes or a few typical and exact embodying the concept of number sense. These instances are compared, and what they have in common is abstracted. Inductively, the definition of number sense is formulated.

\section{METHODOLOGY}

The Preferred Reporting Items for Systematic reviews and Meta-Analyses (PRISMA) statement by Moher, Liberati, Tetzlaff, and Altman (2009) was used as the guidelines for this study. The detailed process of PRISMA was summarized in the flow map (Figure 1).

\section{PRISMA}

PRISMA consist of four distinguish step (identification, screening, eligibility and inclusion) in selecting the best fit document for the purpose systematic literature review (SLRs). Sierra-Correa, Cristina and Kintz (2015) claimed that the PRISMA statement were excellent guidelines in identifying the research questions, addressing the inclusion and exclusion criteria and framing the search. The detailed process of PRISMA adapted from Moher et al. (2009) for this review was summarized in the flow map (Figure 1).

\section{The systematic process of selecting the relevant articles}

Identification: The first step in PRISMA is the 'identification'. The identification of relevant documents involves searching in the selected database using the best-fit term according to the purpose of the study. The challenge in this study was to decide the right term in the search string as number sense was worded differently throughout the literature. For instance, 'sense of number' or 'representation of number' or 'numeracy' or 'numerical sense' always refers to the similar concept with number sense. In this review, 1) to avoid any further confusions of the mentioned variation in the term of number sense with other terms and 2) to specifically refer the exact term used in national early mathematics curriculum in Malaysia, the precise term- 'number sense' per se was searched. As mentioned in Shaffril, Krauss, and Samsuddin (2018), specific keywords will result in more accurate documents. Meanwhile, the other terms that might referred as the similar concept was regarded as the limitation of this review. The Scopus databases were selected to perform this review considering the advantage of this database as compared to others (Burnham, 2006), which means that the other databases were set as limitation of this review.

The relevant articles identified from the "number sense" string were oscillated around title, abstract, and keywords. The total of 650 document appeared in the database registry. Then, the search curtailed with the sampling frame set for this review- the 'primary' year's students. The total of 283 documents were listed including the other terms referred to primary including 


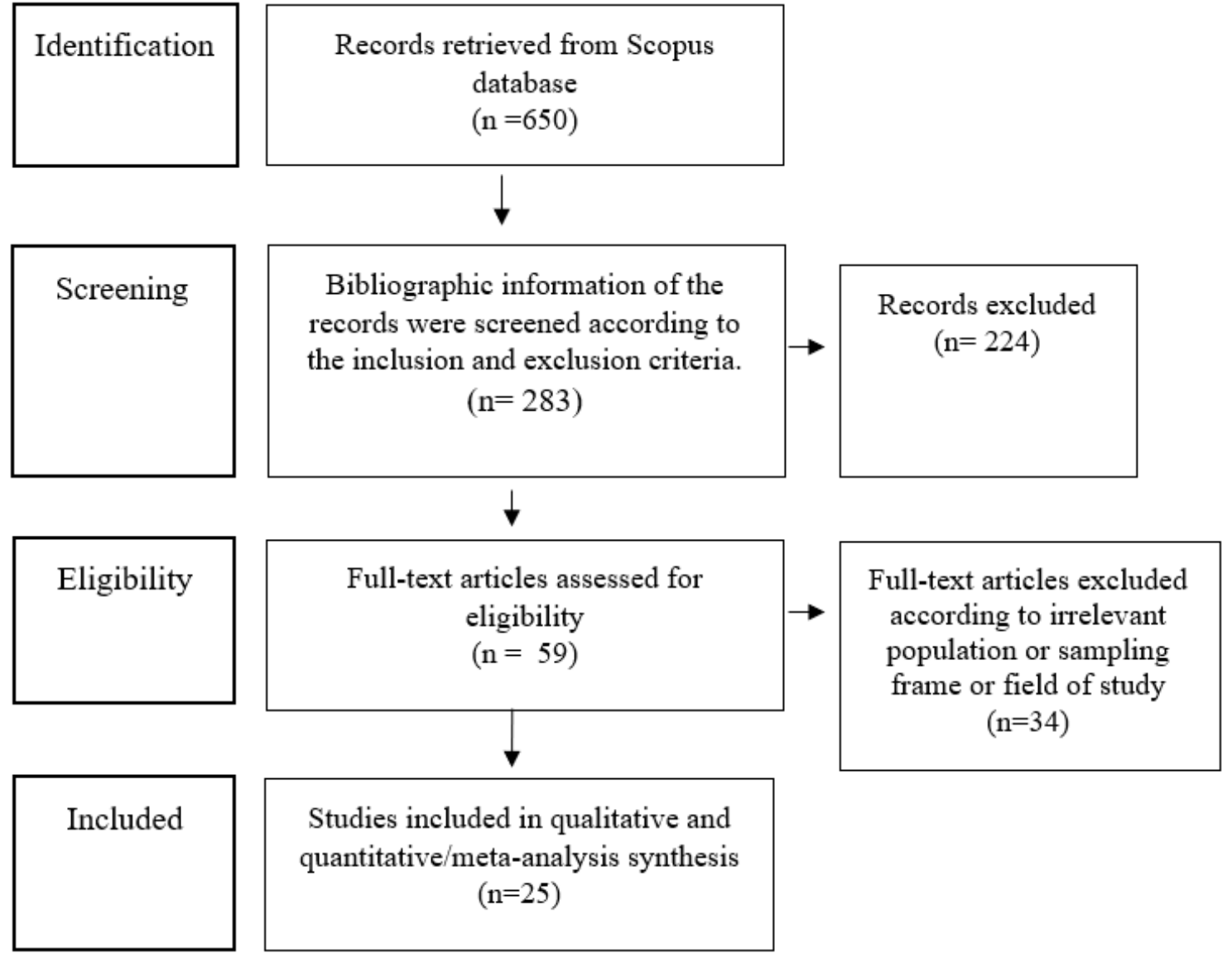

Figure 1. Detailed Process of PRISMA

Table 1. The Inclusion and Exclusion Criteria

\begin{tabular}{lll}
\hline Criterion & Inclusion & Exclusion \\
\hline Document type & Journal articles & Book chapter, conference paper, conference review, review, book and editorial \\
Language & English & Non-English \\
Publication stage & Final & Article In Press \\
Access type & Open Access & Non-Open Access \\
Subject area & Mathematics, Social Science, & Neuroscience, Biochemistry, Genetics and Molecular Biology, Agricultural and \\
& Art and Humanities, & Biological Sciences, Medicine, Immunology and Microbiology, Computer \\
& Psychology, Multidiscipline & Science, Environmental Science, Engineering, Health Professions, \\
\hline
\end{tabular}

'elementary' and 'early'. The searching process was conducted on $5^{\text {th }}$ December 2020.

Screening: The second stage was the 'screening'. Screening involved the filtering process of the identified articles based on the decided inclusion and exclusion criteria. The inclusion criteria for the type of literature were 'open accesses, 'final publication stage', 'only article journal' and language was 'only English'. The exclusion criteria were irrelevant subject areas (i.e., medicine, neuroscience, agricultural and biological sciences, computer science, environmental science, and health professions) to narrow-down the article concerning the number sense studied in primary school children. Meanwhile, Table 1 shows the inclusion and exclusion criteria in this study. From the 283 articles retrieved earlier, a total of 224 unrelated articles were removed.

Eligibility: All the 59 documents were garnered. The review begun with skimming of the retrieved articles, proceed with tabulating the titles, abstracts, objectives, methodology, and conclusions remarks. Hereupon, 34 documents were excluded manually due to irrelevant population frame or field of study, i.e.,

1. deficient in sampling criteria mentioned in the article,

2. pre-service teacher, teacher or parents sampled population rather than the students,

3. the student sample aged between 2-6 years old or 13 years old and above,

4. other than mathematics education field of study (i.e., genetic, neuroscience),

5. non-research article (i.e., review or commentary),

In the end, 25 remaining articles were used as the source meta-analysis and synthesis of study (as illustrated in Figure 1).

Meta-analysis and Synthesis of the Study: The 25 retrieved articles were perused manually. The purposes 
Table 2. The Description of Unit of Analysis, Category and Themes in This Study

\begin{tabular}{ll}
\hline Terms & Description \\
\hline Unit of analysis & The words or phrases in the texts that measure the number sense (i.e., facets, cases, attributes, statements, \\
variables, scale, and construct or criteria). & The constructed conceptual code of number sense that represents the mutually exclusive units of analysis \\
that is directly or indirectly expressed in the text. & \\
Theme & The indicator of the meaning of number sense. The themes synthesized from unified category.
\end{tabular}

of coding were to organize data and summarize the unit of analysis which measure number sense or the components of the number sense in past research. The overall meta-analysis and synthesis of study based on general SLRs guide (i.e., Akcayir \& Akcayir, 2018; Okoli \& Schabram, 2010).

First, the possible codes were scored and listed according to the bibliographic information through open coding, forming an extensive meta-data. The meta-data were re-coded using dichotomous systemic analysis as reported by Tsvetkov (2014). The data-driven codes were constructed a posteriorily, isolated on words or phrases in the texts that refers as number sense or measure the number sense. The initial code serves as unit of analysis were the facets, cases, attributes, statements, variables, scale, and construct or criteria in the documents. The categories were revised, rectified, and refined forming comprehensive categories and several themes. These categories are highlighted in Table 2. The description of the coding process in this study was based on the guide by Vaismoradi, Jones, Turunen, and Snelgrove (2016).

Second, the refined data from the open-coded and meta-data were further organized through the axial coding and selective coding. The emerging individual code was then linked to form a schematic representation of the definition of number sense as stated in Table 3 . The data from the axial and selective codes serves as the descriptor to formulate the definition of number sense in this article. As suggested by Brereton, Kitchenham, Budgen, Turner, and Khalil (2007), the thorough procedure from identification of article until the coding and meta-analysis were checked by all three of the research members.

\section{FINDING AND DISCUSSION}

As the result of open coding, five themes emerged from the indicator of number sense in primary school mathematics education, namely number composition, number identification, number magnitude, number operations, and make a judgment. The number of articles mentioning the codes was counted (n), and the percentage of articles referring to the identified codes was calculated as $\frac{n}{N} \times 100, \mathrm{~N}=25$, the total number of all articles reviewed. Table 3 indicates the emerging themes and category from the open coding.

Based on the finding, it could be analyzed that there were five themes that emerged from 48 categories. The first theme was the number composition which encompassed meaning of numbers, general knowledge of numbers, decomposing and recomposing. Second, number identification was among one the most common unit of analysis for number sense in primary years. Within the number identification category, there were three categories, namely quantity numerical recognition (from visual to verbal), numerical recognition (from verbal to visual), and numeral recognition (from verbal to manipulative). The numerical recognition of number sense from visual to verbal was in term of use context, the distance between, identify a number from pictorial representation, understanding the meaning of variable, structured counting and resultative counting. The numerical recognition from verbal to visual, involved identifying the visual number symbol, matching visual representation, pattern, visual quantity representation, space and space skills. Finally, manipulative utilization within a numeral recognition found as non-verbal number line, use a set of concrete objects, use a set of objects and backward digit span.

Next, third theme was the magnitude of number. Magnitude of number specifically referred to the number order, comparison, and place value. The magnitude of number included order numerals and quantities from least to greatest, symbolic or nonsymbolic comparison, speed and accuracy of identifying and processing number sets, absolute magnitude number, comparison of relative magnitude of numbers, select circle the largest number, cross out the larger, mark the position on a number line, correspondence, seriation (relational skills) and symbolic magnitude comparison. The fourth theme was the number operation. The number operation encompassed the arithmetic operations as the most central theme, among others either non-verbally or and verbally. This category made up with mental computation, pressing a key on a computer keyboard, simple operations, single-digit additions, single-digit subtractions, number relation, multi-digit computation (addition or subtraction), multiplication, division and mix operation. The last theme was the judgment making. The making of judgment included several skills such as subitizing, enumeration, measuring benchmarks, judging the reasonableness, estimates and problem solving using of numbers.

By breaking down the earlier meta-data and the thematic analysis of open coding, the five qualitative themes were fragmented and recoded to form the descriptor for the definition of number sense through the axial code and selective code. The refined codes were 
Table 3. The Emerging Themes and Category from Open Coding

\begin{tabular}{|c|c|c|c|}
\hline $\begin{array}{l}\text { No. Theme } \\
\text { (Indicator) }\end{array}$ & Categories & $\begin{array}{l}\text { Number of } \\
\text { article (n) }\end{array}$ & Source \\
\hline $\begin{array}{l}\text { Number } \\
\text { composition }\end{array}$ & $\begin{array}{l}\text { meaning of numbers, general knowledge } \\
\text { of numbers, decomposing, recomposing }\end{array}$ & $\begin{array}{l}5 \\
(20 \%)\end{array}$ & $\begin{array}{l}\text { Alsawaie (2012), Chen, Li, and Yang (2015), Cheung } \\
\text { and Yang (2018), Lin, Yang, and Li (2016), Sterner, } \\
\text { Wolff, and Helenius (2020) }\end{array}$ \\
\hline $\begin{array}{l}\text { Number } \\
\text { identification }\end{array}$ & $\begin{array}{l}\text { recognizing numbers from visual to } \\
\text { verbal (i.e. use context, the distance } \\
\text { between, identify a number from a } \\
\text { pictorial representation, understanding } \\
\text { the meaning of variable, structured } \\
\text { counting, resultative counting) } \\
\end{array}$ & $\begin{array}{l}7 \\
(28 \%)\end{array}$ & $\begin{array}{l}\text { de León, Jiménez, and Hernández-Cabrera (2020), } \\
\text { Fuson, Caroll, and Drueck (2000), Keijzer, and Terwel } \\
\text { (2003), Sarama, Clements, Swaminathan, McMillen, } \\
\text { and Gomez (2003), Somasundram, Akmar, and Eu } \\
\text { (2019), Sterner et al. (2020), Hornung, Schiltz, Brunner, } \\
\text { and Martin (2014) }\end{array}$ \\
\hline & $\begin{array}{l}\text { recognizing numbers from verbal to } \\
\text { visual (i.e. identify the visual number } \\
\text { symbol, match visual representation, }\end{array}$ & $\begin{array}{l}5 \\
(20 \%)\end{array}$ & $\begin{array}{l}\text { Clarke et al. (2015), Hornung et al. (2014), Sterner et al. } \\
\text { (2020), Wei, Guo, Georgiou, Tavouktsoglou, and Deng } \\
\text { (2018), Yang et al. (2008) }\end{array}$ \\
\hline
\end{tabular}
pattern to numerical, form visual quantity representation, space and space skills) recognizing numbers from verbal to $5 \quad$ Fuson et al. (2000), Guzmán, Rodríguez, Sepúlveda, manipulative (i.e. non-verbal number line, (20\%) and Ferreira (2019), Hornung et al. (2014), Wei et al. use a set of concrete objects, backward (2018), Sterner et al. (2020). digit span)

total 11

Clarke et al. (2015), de Leon et al. (2020), Fuson et al. (2000), Guzman et al. (2019), Hornung et al. (2014), Keijzer, and Terwel (2003), Sarama et al. (2003), Somasundram et al. (2019), Sterner et al. (2020), Wei et al. (2018), Yang et al. (2008)

3 Magnitude order numerals and quantities from least 21 of number to greatest, symbolic or nonsymbolic $(84 \%)$ comparison, speed and accuracy of Anobile, Burr, Iaia, Marinelli, Angelelli, and Turi identifying and processing number sets, absolute magnitude number, comparison of relative magnitude of numbers, select circle the largest number, cross out the larger, mark the position on a number line, correspondence, seriation (relational skills), symbolic magnitude comparison

\begin{tabular}{|c|c|c|c|c|}
\hline 4 & $\begin{array}{l}\text { Arithmetic } \\
\text { operations }\end{array}$ & $\begin{array}{l}\text { mental computation, pressing a key on a } \\
\text { computer keyboard, simple operations, } \\
\text { single-digit additions, single-digit } \\
\text { subtractions, number relation, multi-digit } \\
\text { computation (addition or subtraction), } \\
\text { multiplication, division, mix operation }\end{array}$ & $\begin{array}{l}13 \\
(52 \%)\end{array}$ & $\begin{array}{l}\text { Alsawaie (2012), Chen et al. (2015), Hornung et al. } \\
\text { (2014), Huijsmans et al. (2020), Kuhn and Holling } \\
\text { (2014), Laurillard (2016), Lee, and Lembke (2016), } \\
\text { Sarama et al. (2003), Sasanguie et al. (2013), } \\
\text { Somasundram et al. (2019), Sterner et al. (2020), van } \\
\text { Hoof et al. (2017), Yang et al. (2008) }\end{array}$ \\
\hline 5 & $\begin{array}{l}\text { Make } \\
\text { judgment }\end{array}$ & $\begin{array}{l}\text { subitizing, enumeration, measuring } \\
\text { benchmarks, judging the reasonableness, } \\
\text { estimates, problem soving using of } \\
\text { numbers }\end{array}$ & $\begin{array}{l}13 \\
(52 \%)\end{array}$ & $\begin{array}{l}\text { Alsawaie (2012), Anobile et al. (2018), Chen et al. } \\
\text { (2015), Cheung and Yang (2018), Fuson et al. (2000), } \\
\text { Lin et al. (2016), Sarama et al. (2003), Sasanguie et al. } \\
\text { (2013), Somasundram et al. (2019), Sterner et al. (2020), } \\
\text { Szúcs et al. (2014), Wei et al. (2018), Yang et al. (2008) }\end{array}$ \\
\hline
\end{tabular}

presented in Table 4 . Then, the axial code was linked and represented in the schematic diagram.

The identified emerging codes are labeled as cognition, logic proposition, communication mode, and thinking order which serve as the descriptors of the definition of number sense. The cognition refers to an acquired perception of number and its meanings such as quantity and symbols, in non-electronic form or analogue. Logic preposition is the linkages or interaction in sense-making through logic from the indicator of number sense. For instance, 'conditional implication' contextualizes in a new phenomenon, imparting the idea of number from the concrete to abstract and vice versa.
The communication mode was the route to receive and convey the concept of number sense; language (words, read, write), articulations (verbal, non-verbal) or actions (i.e., pressing key, sign, cue). Meanwhile, the thinking order refers to the verbs used in the hierarchy of the cognitive domain of thinking skills. Thoroughly, all the indicators include both orders of thinking skills, namely Lower-Order Thinking skills (LOTs) and Higher-Order Thinking skills (HOTs), according to the age-based cognitive development of the sampling frame in the respective articles. 
Table 4. The Axial and Selective Codes

\begin{tabular}{|c|c|c|}
\hline Themes from Open Coding & Axial Coding (Descriptor) & Key Terms \\
\hline \multirow[t]{4}{*}{ Number Composition } & Cognition & number, symbol, quantity \\
\hline & Logic preposition & pattern, structure logic \\
\hline & Communication mode & writing, reading, verbal \\
\hline & Thinking order & apply, analyze, synthesize \\
\hline \multirow[t]{4}{*}{ Number Identification } & Cognition & number, symbol, visual, quantity, pictorial, quantity \\
\hline & Logic preposition & $\begin{array}{l}\text { relation of concrete-abstract, relation of abstract-concrete, context, } \\
\text { pattern/structure logic }\end{array}$ \\
\hline & Communication mode & writing, reading, verbal \\
\hline & Thinking order & identify, match, naming, circle, use, counting \\
\hline \multirow[t]{4}{*}{ Magnitude Number } & Cognition & number, symbol/non-symbol, visual, terminology, language, quantity \\
\hline & Logic preposition & $\begin{array}{l}\text { relation of concrete-abstract, a relation of an abstract to the concrete, } \\
\text { pattern/structure logic }\end{array}$ \\
\hline & Communication mode & writing, reading, verbal \\
\hline & Thinking order & compare, choose, name, select, circle, recognize, apply \\
\hline \multirow[t]{4}{*}{ Number Operation } & Cognition & number, quantity, visual, symbol \\
\hline & Logic preposition & the conditional implication, pattern/structure logic \\
\hline & Communication mode & verbal, non-verbal, pressing key, counting \\
\hline & Thinking order & mental computation, counting, memorizing, synthesizing \\
\hline
\end{tabular}

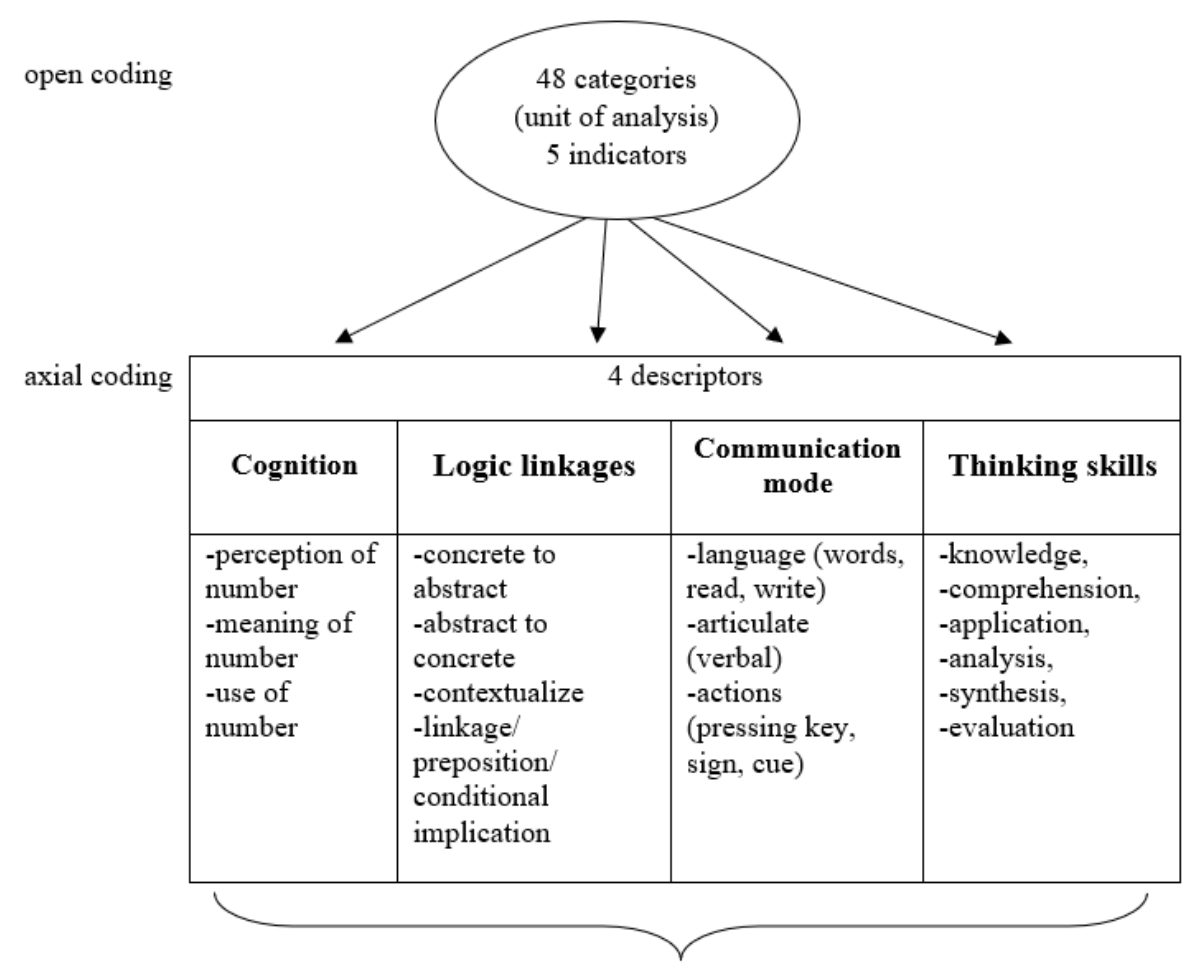

selective coding
Embodied concept: analogous numerical cognition

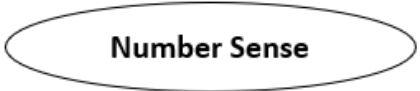

Inductive definition: analogous numerical cognition, perceived via logical linkages and thinking skills through various communication modes.

Figure 2. Schematic Diagram of the Number Sense Definition Formulation

Finally, throughout all the codes, the core themes emerged were labeled as the analogous numerical cognition. As the research in mathematics education has seemed to categorize the indicator of number sense complexity according to age, the analogous numerical cognition was a broad term referred as the biological or natural human perception of numerical conception acquired in primary school years. The emerging codes were then linked to form a schematic diagram of the formulation of number sense as in Figure 2-that consisted of cognition, logic proposition, communication mode, and thinking order.

Therefore, the definition of number sense was: 


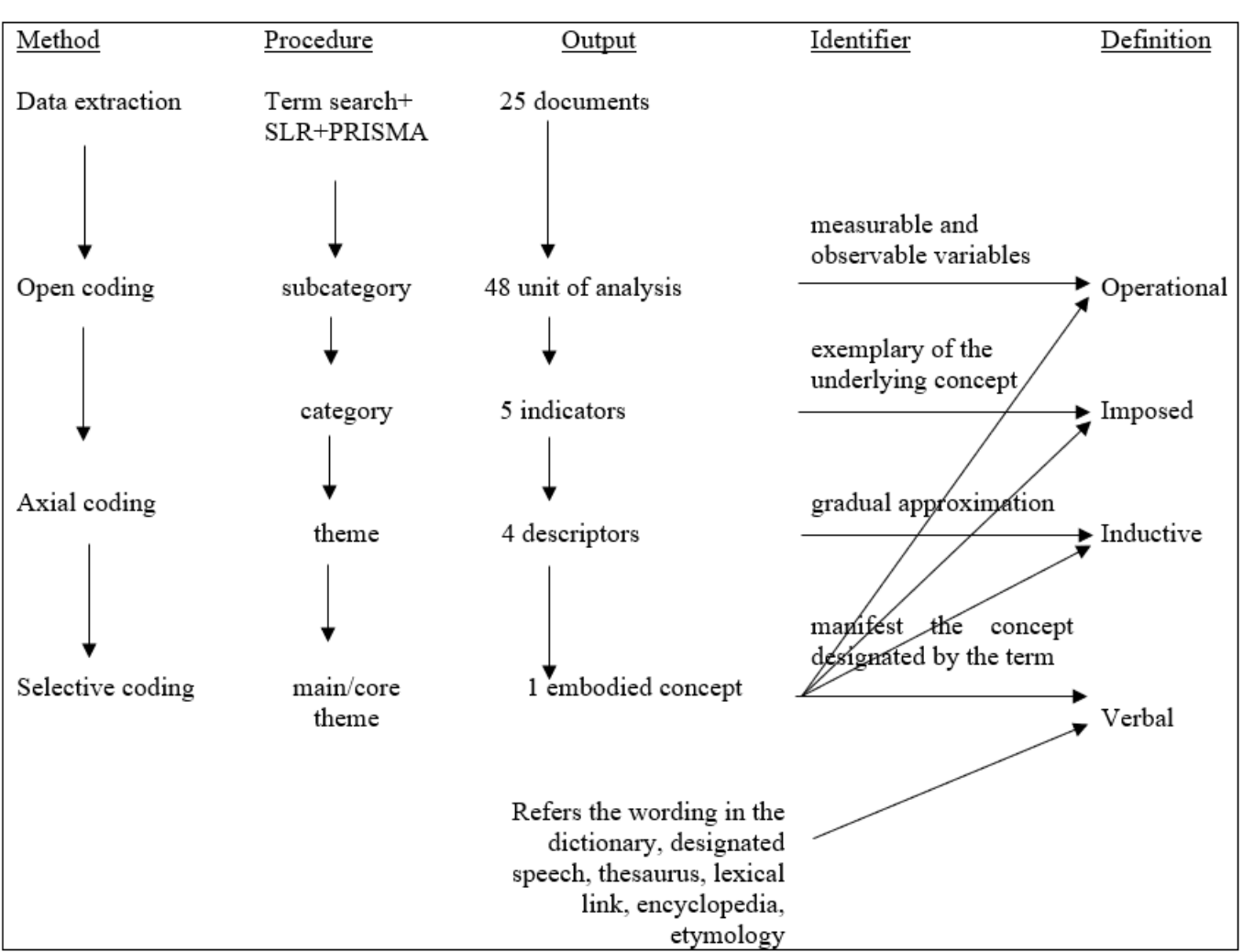

Figure 3. Flowchart of procedure for systematic definition formulation using SLR+PRISMA for number sense

Number sense was an analogous numerical cognition, perceived via logical preposition and thinking skills through various communication modes.

From the analysis, the core theme identified throughout all the subcategories, categories, and themes was the 'analogous numerical cognition.' This core theme was anchored as the basis of all types of number sense. Thus, from the analysis conducted from this study, the definitions that encompassed operational definition, imposed definition, inductive definition and verbal definition. Thus, the typology of definition for number sense in this article were:

\section{The Operational Definition of Number Sense}

Number sense was an analogous numerical cognition collectively measured by any or all 48 units of analysis includes facets, cases, attributes, statements, variables, scale, and construct or criteria of number sense as identified in this article.

\section{The Imposed Definition of Number Sense}

Number sense is an analogous numerical cognition that includes number composition, number identification, magnitude number, number operation, and judgment making.

\section{The Inductive Definition of Number Sense}

Number sense is an analogous numerical cognition, perceived via logical preposition and thinking skills, channeled in/out through various communication modes.

\section{The Verbal Definition of Number Sense}

Number sense is an analogous numerical cognition that denotes a particular meaning to a group of vital mathematical abilities or the basic mathematical concept. In other words, number sense may also be used loosely to refer to an intelligible view of number implied or grasped rather than expressed.

\section{Discussion, Conclusion and Recommendation for Future Research}

This study carefully extracted five indicators and 48 unit of analysis of number sense that could further operationalize to serve as cases, attributes, statements, variables, and embodied ideas for future research in primary year's education. Practically, the teacher could use the indicators in the teaching practice to create a sound-plan for better understanding of children's acquiring number sense for primary school students, with the support of other research findings as well. Even though this study identified and accumulated the indicators in number sense in the past studies according to primary years schooling, it was an insufficient evident on which indicators that were relevant for each grade respectively. Bridging this gap in future studies would be able to provide a much comprehensive guide for teaching number sense systematically.

This study proposed the definition of number sense. Besides the induced definition, the imposed, operational, and verbal definitions were also formulated in conjunction to the primary years' education. The finding from this review further supported the statement 
by Leibovich et al. (2017) who found that there was not enough convincing evidence to relates number sense theory exclusively with 'innate and non-symbolic' ability. In this review, the primary year's number senses were extended into symbolic ability as well. In a similar vein, the reviews of past research the context of primary school years, found that number sense were rather acquired by students and facilitated by the means of early mathematics education. Another important signposting from this study is the emergence of cognition and logic preposition as the descriptor of number sense.

Towards the completion of the definition formulation, this study also developed a flowchart for definition formulation using SLR+PRISMA through three coding stages. The proposed definition and flowchart of the process have important implications for advancing research on this topic. Even it is so, the definition of number sense in this article is limited for primary school years and there is a need to consider the underexplored forms of the definition of number sense related to several factors such as context, ageism, multiple intelligence, worldviews, and even biological factors. Moreover, number sense in young children should be studied carefully that denotes their budding development.

Author contributions: All authors have sufficiently contributed to the study, and agreed with the results and conclusions.

Funding: No funding source is reported for this study.

Declaration of interest: No conflict of interest is declared by authors.

\section{REFERENCES}

Akçayır, G., \& Akçayır, M. (2018). The flipped classroom: A review of its advantages and challenges. Computers $\mathcal{E}$ Education, 126, 334-345. https://doi.org/10.1016/j.compedu.2018.07.021

Alsawaie, O. N. (2012). Number sense-based strategies used by high-achieving sixth grade students who experienced reform textbooks. International Journal of Science and Mathematics Education, 10(5), 10711097. https:/ / doi.org/10.1007/s10763-011-9315-y

Anobile, G., Burr, D. C., Iaia, M., Marinelli, C. V., Angelelli, P., \& Turi, M. (2018). Independent adaptation mechanisms for numerosity and size perception provide evidence against a common sense of magnitude. Scientific Reports, 8(1), 13571. https:/ / doi.org/10.1038/s41598-018-31893-6

Baroody, A. J., Eiland, M., \& Thompson, B. (2009). Fostering at-risk preschoolers' number sense. Early Education and Development, 20(1), 80-128. https:/ / doi.org/10.1080/10409280802206619

Brankaer, C., Ghesquière, P., \& De Smedt, B. (2017). Symbolic magnitude processing in elementary school children: A group administered paper-andpencil measure (SYMP Test). Behavior research methods, 49(4), 1361-1373. https:/ / doi.org/10.3758/ s13428-016-0792-3

Brereton, P., Kitchenham, B. A., Budgen, D., Turner, M., \& Khalil, M. (2007). Lessons from applying the systematic literature review process within the software engineering domain. Journal of Systems and Software, 80(4), 571-583. https://doi.org/10.1016/ j.jss.2006.07.009

Burnham, J. F. (2006). Scopus database: a review. Biomedical Digital Libraries, 3(1), 1. https:/ / doi.org/ 10.1186/1742-5581-3-1

Carroll, W. M., Fuson, K. C., \& Diamond, A. (2000). Use of student-constructed number stories in a reformbased curriculum. The Journal of Mathematical Behavior, 19(1), 49-62. https://doi.org/10.1016/ S0732-3123(00)00038-9

Cheek, K. A. (2013). How geoscience novices reason about temporal duration: The role of spatial thinking and large numbers. Journal of Geoscience Education, 61(3), 334-348.

Chen, F., Yan, Y., \& Xin, T. (2016). Developing a learning progression for number sense based on the rule space model in China. Educational Psychology, 37(2), 128-144.

https:/ / doi.org/10.1080/01443410.2016.1239817

Cheung, K. L., \& Yang, D.-C. (2018). Examining the Differences of Hong Kong and Taiwan Students' Performance on the Number Sense Three-tier Test. EURASIA Journal of Mathematics, Science and Technology Education, 14(7), 3329-3345. https://doi.org/10.29333/ ejmste/91682

Chikiwa, S., Westaway, L., \& Graven, M. (2019). What mathematics knowledge for teaching is used by a Grade 2 teacher when teaching counting. South African Journal of Childhood Education, 9(1), 1-9. https:/ / doi.org/10.4102/ sajce.v9i1.567

Chun Tie, Y., Birks, M., \& Francis, K. (2019). Grounded theory research: A design framework for novice researchers. SAGE open medicine, 7, 2050312118822927.

Clarke, B., Baker, S., Smolkowski, K., Doabler, C., Strand Cary, M., \& Fien, H. (2015). Investigating the efficacy of a core kindergarten mathematics curriculum to improve student mathematics learning outcomes. Journal of Research on Educational Effectiveness, 8(3), 303-324. https:/ / doi.org/10.1080 /19345747.2014.980021

Clarke, B., Shanley, L., Kosty, D., Baker, S. K., Cary, M. S., Fien, H., \& Smolkowski, K. (2018). Investigating the incremental validity of cognitive variables in early mathematics screening. School Psychology Quarterly, 33(2), 264-271. https:/ / doi.org/10.1037/ spq0000214 
Conant, L. L (1893). Primitive number systems. Smithsonian Institution: United States Congressional Serial Set, Volume 3131.

Courtney-Clarke, M., \& Wessels, H. (2014). Number sense of final year pre-service primary school teachers. Pythagoras, 35(1), 1-9. https://doi.org/ 10.4102/ pythagoras.v35i1.244

Crawley, E. S. (1897). Popular Science Monthly Volume 51 August 1897 - The Origin and Development of Number Systems 1897. Popular Science Monthly, 51.

Crawley, E., \& Karpinski, L. (2019). Origin and Development of Number Systems. LM Publishers.

Creswell, J. W (2009). Research design: Qualitative, quantitative, and mixed methods approaches (3rd Ed.). Sage publications.

de León, S. C., Jiménez, J. E., \& Hernández-Cabrera, J. A. (2020). Confirmatory factor analysis of the indicators of basic early math skills. Current Psychology, 1-12.

Dehaene, S. (2011). The Number Sense: How the Mind Creates Mathematics. OUP, USA.

Diezmann, C. M., \& English, L. D. (2001). Developing young children's multidigit number sense. Roeper Review, 24(1), 11-13. https://doi.org/10.1080/ 02783190109554118

Dunphy, E. (2007). The primary mathematics curriculum: Enhancing its potential for developing young children's number sense in the early years at school. Irish Educational Studies, 26(1), 5-25. https:/ / doi.org/10.1080/03323310601125088

Fuson, K. C., Caroll, W. M., \& Drueck, J. V. (2000). Achievement results for second and third graders using the Standards-based curriculum Everyday Mathematics. Journal for Research in Mathematics Education, 31(3), 277-295. https:/ / doi.org/10.2307/ 749808

Gavel, Y., \& Iselid, L. (2008). Web of Science and Scopus: a journal title overlap study. Online information review, 32(1), 8-21. https://doi.org/10.1108/ 14684520810865958

Ghazali, M. (2004). An exploratory study into Malaysian children's understanding of multiple representation strand on number sense. Jurnal Pendidik Dan Pendidikan, 33-46.

Gifford, S. (2014). A good foundation for number learning for five-year-olds? An evaluation of the English Early Learning 'Numbers' Goal in the light of research. Research in Mathematics Education, 16(3), 219-233. https:/ / doi.org/10.1080/14794802.2014.895677

Gupta, A. (2019). Definitions, The Stanford Encyclopedia of Philosophy (Winter 2019 Edition), Edward N. Zalta (Ed.). https://plato.stanford.edu/archives/ win2019/entries/definitions/
Guzmán, B., Rodríguez, C., Sepúlveda, F., \& Ferreira, R. A. (2019). Number sense abilities, working memory and RAN: A longitudinal approximation of typical and atypical development in chilean children. Revista de Psicodidáctica (English ed.), 24(1), 62-70. https:/ / doi.org/10.1016/j.psicoe.2018.11.003

Hornung, C., Schiltz, C., Brunner, M., \& Martin, R. (2014). Predicting first-grade mathematics achievement: the contributions of domain-general cognitive abilities, nonverbal number sense, and early number competence. Frontiers in Psychology, 5. https:/ / doi.org/10.3389/fpsyg.2014.00272

Howell, S. C., \& Kemp, C. R. (2010). Assessing preschool number sense: Skills demonstrated by children prior to school entry. Educational Psychology, 30(4), 411-429.

https:/ / doi.org/10.1080/01443411003695410

Huijsmans, M. D. E., Kleemans, T., van der Ven, S. H. G., \& Kroesbergen, E. H. (2020). The relevance of subtyping children with mathematical learning disabilities. Research in Developmental Disabilities, 104, 103704. https://doi.org/10.1016/j.ridd.2020. 103704

Karsenty, R. (2014). Mathematical ability. In S. Lerman (Ed.), Encyclopedia of mathematics education (pp. 579582). Springer.

Keijzer, R., \& Terwel, J. (2003). Learning for mathematical insight: A longitudinal comparative study on modelling. Learning and Instruction, 13(3), 285-304. https://doi.org/10.1016/S0959-4752(02) 00003-8

Kermani, H. (2017). Computer Mathematics Games and Conditions for Enhancing Young Children's Learning of Number Sense. Malaysian Journal of Learning and Instruction, 14(2), 23-57.

Kerschen, K., Cooper, S., Shelton, R., \& Scott, L. (2018). The impact of a summer mathematics academy on rising kindergartners' understanding of early number concepts. Journal of Research in Childhood Education, 32(4), 419-434. https:/ / doi.org/10.1080/ 02568543.2018.1497738

Kim, D., Shin, J., \& Lee, K. (2013). Exploring latent class based on growth rates in number sense ability. Asia Pacific Education Review, 14(3), 445-453. https:/ / doi.org/10.1007/s12564-013-9274-9

Kinzie, M. B., Whittaker, J. V., Williford, A. P., DeCoster, J., McGuire, P., Lee, Y., \& Kilday, C. R. (2014). MyTeachingPartner-Math/Science prekindergarten curricula and teacher supports: Associations with children's mathematics and science learning. Early Childhood Research Quarterly, 29(4), 586-599. https://doi.org/10.1016/j.ecresq. 2014.06.007

Kuhn, J.-T., \& Holling, H. (2014). Number sense or working memory? The effect of two computer- 
based trainings on mathematical skills in elementary school. Advances in Cognitive Psychology, 10(2), 59-67. https:/ / doi.org/10.5709/acp-0157-2

Kuldas, S., Sinnakaudan, S., Hashim, S., \& Ghazali, M. (2017). Calling for the development of children's number sense in primary schools in Malaysia. Education 3-13, 45(5), 586-598. https://doi.org/ $10.1080 / 03004279.2016 .1143521$

Labinowicz, E. (1980). The Piaget Primer: Thinking, Learning, Teaching. Addison-Wesley Publishing Company, Inc.

Laurillard, D. (2016). Learning number sense through digital games with intrinsic feedback. Australasian Journal of Educational Technology, 32(6), 32-44. https://doi.org/10.14742/ajet.3116

Lee, Y. S., \& Lembke, E. (2016). Developing and evaluating a kindergarten to third grade CBM mathematics assessment. ZDM, 48(7), 1019-1030. https: / / doi.org/10.1007/s11858-016-0788-6

Leibovich, T., Katzin, N., Harel, M., \& Henik, A. (2017) From "sense of number" to "sense of magnitude": The role of continuous magnitudes in numerical cognition. Behavioral and Brain Sciences, 40, e164. https:/ / doi.org/10.1017/S0140525X16000960

Linder, S. M., Powers-Costello, B., \& Stegelin, D. A. (2011). Mathematics in early childhood: Researchbased rationale and practical strategies. Early Childhood Education Journal, 39(1), 29-37. https: / / doi.org/10.1007/s10643-010-0437-6

Lyublinskaya, I. (2009). Developing Number Sense with Technology-Based Science Experiments: Reflections on Classroom Practice in Primary Grades and Pre-service Education. Mathematics Teaching-Research Journal Online, 3(2), 1-14.

Mejias, S., Muller, C., \& Schiltz, C. (2019). Assessing Mathematical School Readiness. Frontiers in Psychology, 10, 1173. https://doi.org/10.3389/ fpsyg.2019.01173

Moher, D., Liberati, A., Tetzlaff, J., Altman, D. G., \& Prisma Group. (2009). Preferred reporting items for systematic reviews and meta-analyses: the PRISMA statement. PLoS medicine, 6(7), e1000097.

NCTM (National Council of Teachers of Mathematics) (2000). Principles and Standards for School Mathematics. NCTM.

Okoli, C., \& Schabram, K. (2010). A Guide to Conducting a Systematic Literature Review of Information Systems Research. SSRN Electronic Journal. https:// doi.org/10.2139/ssrn.1954824

Ottmar, E. R., Konold, T. R., Berry, R. Q., Grissmer, D. W., \& Cameron, C. E. (2014). Evaluating the structure of the Mathematics Teacher Questionnaire: A measure of exposure to mathematics instructional practices and content.
Learning Environments Research, 17(1), 127-138. https:/ / doi.org/10.1007/s10984-013-9147-5

Pitta-Pantazi, D. (2014). Mathematical ability. In: S. Lerman (Ed.), Encyclopedia of mathematics education (pp. 470-474). Springer.

Planas, N., \& Schütte, M. (2018). Research frameworks for the study of language in mathematics education. ZDM, 50(6), 965-974. https://doi.org/ 10.1007/s11858-018-0997-2

Rendell, G. (2008). Learning fraction sense: Applying Piaget's operative theory of meaning in a multi agent system to overcome the learning paradox. International Journal of Learning, 15(2).

Reynvoet, B., Smets, K., \& Sasanguie, D. (2016). "Number Sense": What's in a Name and Why Should We Bother? In Continuous Issues in Numerical Cognition (pp. 195-214). Elsevier. https: / / doi.org/10.1016/B978-0-12-801637-4.00009-3

Riess, A. (1943). Numerical quantification vs. number sense. The Journal of Psychology, 15(1), 99-108.

São José, J. M. S., Amado, C. A. F., Ilinca, S., Buttigieg, S. C., \& Taghizadeh Larsson, A. (2019). Ageism in health care: a systematic review of operational definitions and inductive conceptualizations. The Gerontologist, 59(2), e98-e108.

Sarama, J., Clements, D. H., Swaminathan, S., McMillen, S., \& Gonzalez Gomez, R. M. (2003). Development of mathematical concepts of two-dimensional space in grid environments: An exploratory study. Cognition and Instruction, 21(3), 285-324. https: / / doi.org/10.1207/S1532690XCI2103_03

Sasanguie, D., Göbel, S. M., Moll, K., Smets, K., \& Reynvoet, B. (2013). Approximate number sense, symbolic number processing, or number-space mappings: What underlies mathematics achievement? Journal of Experimental Child Psychology, 114(3), 418-431. https://doi.org/ 10.1016/j.jecp.2012.10.012

Schacter, J., \& Jo, B. (2017). Improving preschoolers' mathematics achievement with tablets: a randomized controlled trial. Mathematics Education Research Journal, 29(3), 313-327. https://doi.org/ 10.1007/s13394-017-0203-9

Schacter, J., Shih, J., Allen, C. M., DeVaul, L., Adkins, A. B., Ito, T., \& Jo, B. (2016). Math shelf: A randomized trial of a prekindergarten tablet number sense curriculum. Early Education and Development, 27(1), 74-88.

https:/ / doi.org/10.1080/10409289.2015.1057462

Sengul, S. (2013). Identification of Number Sense Strategies used by Pre-service Elementary Teachers. Educational Sciences: Theory and Practice, 13(3), 1965-1974. https://doi.org/10.12738/ estp.2013.3.1365 
Shaffril, H. A. M., Krauss, S. E., \& Samsuddin, S. F. (2018). A systematic review on Asian's farmers' adaptation practices towards climate change. Science of the Total Environment, 644, 683-695.

Shoemaker, P. J., Tankard Jr, J. W., \& Lasorsa, D. L. (2003). How to build social science theories. Sage publications.

Sierra-Correa, P. C., \& Kintz, J. R. C. (2015). Ecosystembased adaptation for improving coastal planning for sea-level rise: A systematic review for mangrove coasts. Marine Policy, 51, 385-393.

Sterner, G., Wolff, U., \& Helenius, O. (2020). Reasoning about Representations: Effects of an Early Math Intervention. Scandinavian Journal of Educational Research, 64(5), 782-800. https://doi.org/10.1080/ 00313831.2019.1600579

Szŭcs, D., Devine, A., Soltesz, F., Nobes, A., \& Gabriel, F. (2014). Cognitive components of a mathematical processing network in 9-year-old children. Developmental Science, 17(4), 506-524. https:/ / doi.org/10.1111/desc.12144

Timasheff, N. S. (1947). Definitions in the social sciences. American Journal of Sociology, 53(3), 201-209.

Tsvetkov, V. Y. (2014). Dichotomous Systemic Analysis. Life Science Journal, 11, 586-590.

Vaismoradi, M., Jones, J., Turunen, H., \& Snelgrove, S. (2016). Theme development in qualitative content analysis and thematic analysis. Journal of Nursing Education and Practice, 6(5), 100-110. https:/ / doi.org/10.5430/jnep.v6n5p100

Van Hoof, J., Verschaffel, L., \& Van Dooren, W. (2017). Number sense in the transition from natural to rational numbers. British Journal of Educational Psychology, 87(1), 43-56. https://doi.org/10.1111/ bjep.12134

Verschaffel, L., Greer, B., \& Torbeyns, J. (2006). Numerical thinking. In A. Gutie'rrez, \& P. Boero (Eds.), Handbook of research on the psychology of mathematics education: past, present and future (pp. 5182). Sense Publishers.
Verschaffel, L., Greer, B., and De Corte, E. (2017). Whole number concepts and operations. In F. K. Lester (Ed.), Second handbook of research on mathematics teaching and learning (pp. 557-628). IAP.

Voronin, I. A., Ovcharova, O. N., Bezrukova, E. M., \& Kovas, Y. (2018). Cognitive and non-cognitive predictors of the unified state exam performance of students from schools with regular and advanced mathematical curricula. Psychology in Russia: State of the art, 11(4), 177-199. https://doi.org/10.11621/ pir.2018.0412

Wright, B. (1994). Mathematics in the lower primary years: A research-based perspective on curricula and teaching practice. Mathematics Education Research Journal, 6(1), 23-36. https://doi.org/ 10.1007/BF03217260

Xinkui, L. (2016). From" Evolution of Literature" to" Bias of Perspective": Imposed Interpretation and the Definition of Literary Theory. Journal of Graduate School of Chinese Academy of Social Sciences, 01.

Yang, D. C., \& Hsu, C. J. (2009). Teaching number sense for 6th graders in Taiwan. International Electronic Journal of Mathematics Education, 4(2), 92-109.

Yang, D. C., Li, M. N., \& Lin, C. I. (2008). A study of the performance of 5 th graders in number sense and its relationship to achievement in mathematics. International Journal of Science and Mathematics Education, 6(4), 789-807. https://doi.org/10.1007/ s10763-007-9100-0

Yilmaz, Z. (2017). Young children's number sense development: Age related complexity across cases of three children. International Electronic Journal of Elementary Education, 9(4), 891-902.

Zanzali, N. A. A., \& Ghazali, M. (1997). Assessment of school children's number sense. Proceedings of the International Conference on Mathematics Education into the 21st Century: Societal Changes: Issues and Approaches.

\section{http://www.ejmste.com}

